San Jose State University

SJSU ScholarWorks

\title{
Pricing in Online Auction Procurement: A Review of Empirical Methods and Current Understandings
}

\author{
Ming Zhou \\ San Jose State University \\ William Y. Jiang \\ San Jose State University, william.jiang@sjsu.edu \\ M. Cao
}

Follow this and additional works at: https://scholarworks.sjsu.edu/org_mgmt_pub

Part of the Business Commons

\section{Recommended Citation}

Ming Zhou, William Y. Jiang, and M. Cao. "Pricing in Online Auction Procurement: A Review of Empirical Methods and Current Understandings" International Journal of Innovation and Technology Management (2012): 1-17. https://doi.org/10.1142/S0219877012500174

This Article is brought to you for free and open access by the School of Management at SJSU ScholarWorks. It has been accepted for inclusion in Faculty Publications, School of Management by an authorized administrator of SJSU ScholarWorks. For more information, please contact scholarworks@sjsu.edu. 


\title{
PRICING IN ONLINE AUCTION PROCUREMENT
}

\section{A Review of Empirical Methods and Current Understandings}

\author{
Ming Zhou, Ph.D. \\ Assistant Professor of Supply Chain and Operations Management \\ Department of Organizations and Management \\ Lucas Graduate School of Business \\ College of Business \\ San José State University \\ BT 659, One Washington Square \\ San José, CA, 95192 - 0070 USA \\ Phone : 408-924-3572 \\ Email: ming.zhou@sjsu.edu
}

*William Y Jiang, Ph.D.

Professor of Strategic Management and Department Chair

Department of Organizations and Management

Lucas Graduate School of Business

College of Business

San José State University

One Washington Square

San José, CA, 95192 - 0070 USA

Phone : 408-924-3551

Email: william.jiang@sjsu.edu

Menglin Cao, Ph.D.

Vice President

Credit Risk Management

Wells Fargo Bank

525 Market Street, $23^{\text {rd }}$ Floor

San Francisco, CA, 94105 USA

Phone: 415-947-5926

Email: Menglin.cao@wellsfargo.com

* The corresponding author 


\title{
PRICING IN ONLINE AUCTION PROCUREMENTS: A REVIEW OF EMPIRICAL METHODS AND CURRENT UNDERSTANDINGS
}

\begin{abstract}
The online auction has become an important channel for procurement and sourcing management. As firms often expect lower procurement prices through online auctions, how the prices are determined in online auctions should be of major interest to procurement managers and supply chain researchers. Despite the abundant empirical studies on online auction prices, an aggregated view is still absent. This study fills this gap with a review of extant studies. More specifically, this study provides summaries all major theories behind online auction pricing, defines and analyzes often encountered econometric issues, and discusses how the treatments of these issues have been operationalized. Towards the end, existing findings on determinants of online auction prices are integrated and examined. The purpose of this study is to provide a convenient and precise package of current studies for researchers and professionals.
\end{abstract}

\section{Introduction}

Auction is nothing new to the business world. The first known auction dates back to Bablyon, 500 B.C. In the modern world, auctions are witnessed in many contexts, such as spectrum auction, commodities auction, and real property auction. However, logistics/supply chain management via online auctions is still a novelty to many business professionals. The online platform serves as an intermediary that aggregates demand and supply [Bakos (1998); Brynjolfsson and Smith (2000)], where the auction mechanism best reveals the market value of a product or a service. Hence, online auctions have been introduced as a solution to many logistics/supply chain issues. One of the most important uses of these mechanisms is the determination of the most suitable supplier of a product or service. For instance, freighttraders.com finds the best carrier for a shipper using its online auction community. One of the users left the following comments after using freight-traders.com: 
"Freight Traders was our first experience of web-based transport buying and it was a great success. It gave us a new perspective in terms of accessing a large pool of carriers, across Europe, who were previously unknown to us. Even though we did not always choose the lowest bid, the savings achieved far exceeded our expectations..." (Eddy Sheerlinck, director of procurement).

Other applications of online auctions include depleting excessive inventories, trading unused manufacturing capacities, procuring indirect supplies such as maintenance, repair and operating (MRO) products. [Kaplan and Sawhney (2000); Germer, Carter and Kauffman (2004); Johnson and Klassen (2005)]. The prevalence of online auctions provides unprecedented opportunities to link traders and automate transactions, which further help businesses to identify new business opportunities as well as streamline their supply chain operations [Boyer and Olson (2002); Simchi-Levi, Kaminsky and Simchi-Levi (2003); Emiliani and Stec (2002)].

One of the major benefits of using online auctions is the reduced procurement cost [Murphy, Soni and Ghosh (2004)], where the procurement price is often lower than what the firms have to pay through traditional procurement channels. The savings from low procurement prices can then impact the overall operations/logistics cost [Ellram (1996); Kawtummachai and Hop (2005)]. Hence, all participants of online auctions should thoroughly understand the pricing mechanism in online auctions in order to shape a reasonable expectation on the savings and to better utilize the online auction channel.

Many researchers designed studies to explore the pricing mechanism in online auctions [Houser and Wooders (2000); Bajari and Hortacsu (2002); Yin (2004)], and most of the extant studies used online auction data to estimate the price determinants or to test how much one or more factors may influence the final price. For a procurement manager, such empirical estimations are of practical significance in that the individual effects and possible interactions among the determinants reveal the underlying pricing process. Despite the abundant literature in 
testing online auction prices, a systematic view of online auction pricing is still non-existent. The missing of a systematic view hampers the selection of appropriate estimation methods and the development of an aggregated understanding on estimating online auction prices. In addition, the auction participants also need to comprehend the consequences and tradeoffs of selecting one method versus the other. In this study, major theories are reviewed and summarized with respect to their relevance to online auction pricing and research applications. Statistical/econometric issues that the existing research encountered are also defined and analyzed. More importantly, the study also looks at how the treatments of the statistical/econometric issues were operationalized by existing studies. The potential benefits and weaknesses of the treatments are also clearly presented. Current price determinants in online auctions are summarized and discussed. The purpose of this study is to provide a convenient and precise guide for future researchers and professionals that attempt to understand online auction pricing and its estimation.

The findings here are more applicable to large scale online auction markets, such as the content-based e-markets defined by Smichi-Levy et al. [2003]. These markets bear great resemblance to eBay like markets where a large number of suppliers and buyers trade. More often than not, the auctions are single unit auctions rather than multi-unit auctions [Bapna, et al. (2002)]. Furthermore, most of the current studies are based on data from eBay, which is often viewed as a B2C site. Although business auctions differ from consumer auctions in many ways, the theories, econometric/statistic issues due to the auction structure, and solutions to these estimation issues are still similar. Price determinants may not be exactly the same, but the current findings should be close proxies given the paucity of empirical works using B2B data. The literature review provides managerial insights from extant studies for procurement professionals when they participate in online auctions. 
In the next section, major theories relevant to online auction pricing are reviewed. In section three, statistical/econometric methods and models are summarized and discussed. Major determinants of online auction pricing are identified in section four. The last section concludes the paper with our findings and conclusions.

\section{Theoretical Backgrounds of Online Auction Pricing}

A brief introduction to the theoretical backgrounds of extant empirical studies is presented in this section. This section builds a starting block to better understand the empirical model specifications and econometric issues in the method and solution section.

\subsection{The Hedonic Price Perspective:}

Pricing would not be interesting if all goods were homogeneous. Realistically, products are often differentiated in real life. In order to understand pricing for different goods, Rosen [1974] took a hedonic price perspective and conceptualized product values in terms of a few underlying characteristics $\left(z_{1}, \ldots, z_{n}\right)$ that embody the differentiated goods. For example, a car's engine, transmission, and safety features characterize the car's market value. Estimating hedonic prices makes it possible to identify the extent to which specific attributes affect the price of a product [Forgionne (1996); Lancaster (1966)], such as the calculation process of price indices and housing prices [Pakes (2001); Martins-Filho and Bin (2005)].

Due to its intuitive and straightforward nature, most research in online auction pricing more or less adopts the hedonic approach and includes variables to reflect the hedonic pricing mechanism [Kalyanam and McIntyre (2001); Melnik and Alm (2002); Zhou, Dresner and Windle (2009); Yin (2004)]. For example, Yin (2004) estimated a hedonic price function, where 
computers were characterized by processor models, processor speed, and hard disk capacity. Another example is pricing based on product condition. It is always necessary for a procurement manager to understand the fair value of a product and the effect of its possible variations. The hedonic results establish the market price or the market value for the variations due to parts, functions, or characteristic changes, where the values can be hard to ascertain if they are not normally traded separately.

\subsection{Information Structure and Online Auction Specifications:}

The second theoretical base for online auction pricing comes, not surprisingly, from the auction theory. Research on auctions is a vast area that studies the price formation mechanisms under a chosen auction form given product value heterogeneity [Milgrom (2004)]. One aspect of the online auctions that has drawn attentions from current empirical studies is the issue of information structure: an auction is defined as a private value auction if bidders' valuations on an item are independent from each other and a bidder is aware of his/her own valuation only, just as the derived satisfaction for a non-durable good is only a personal matter. In contrast, an auction is defined as a common value auction, where the item auctioned has a common value, regardless of whether this value is made public to all bidders. For example, an auction for the right to a piece of land under which a coalmine lies is a common value auction [Milgrom and Weber (1982)].

One direct result of the information structure is the effect of the number of bidders on the ending price of an auction. The number of bidders should increase the ending price in private value auctions as a natural result of ordered statistics. However, more bidders can decrease the ending price under a common value assumption [Yin (2004)]. The price decreasing effect of the 
number of bidders exists because of the bidders' concern for winner's curse [Capen, Clapp and Campbell (1971); Fudenberg and Tirole (2000)]. A winner's curse occurs when a bidder realizes the bid is above the value of what the item is really worth. In the case of a coal mine, the overall value of the coal mine may be $\$ 2$ million, the bidder that won the auction with a $\$ 2.1$ million surely paid too much. A rational bidder would bid more conservatively by anticipating the risk of winner's curse [Bajari and Hortacsu (2002)]. Hence, the price decreasing effect of the number of bidders has been used as an indicator for the existence of winner's curse [Paarsch (1992)]. However, Milgrom and Weber [1982] suggest that the winner's curse is weakened in an English auction where a bidder is able to scrutinize bids placed by his competitors. Therefore, the fact that increasing number of bidders will always be detrimental to the seller profit, or the bidder surplus, is still uncertain.

The common value of an object, if applicable, should be well controlled. Higher common value certainly deserves a higher ending price. The retail price and/or the manufacturer suggested retail prices (MSRP) are normal proxies for the common value [Lucking-Reiley et al. (2000); Houser and Wooders (2000); Livingston (2005) etc.]. The retail price/MSRP is information easily observable to all bidders before they actually participate in an auction. It helps formulate an expectation on the common value. Yin [2004] structures a different measure, in which a survey on personal computer users was conducted to collect public value information. The findings of this study suggest that the value established by the survey should be a good indicator of the common value as long as the survey respondents possess no systematic difference from the actual bidders.

Besides the information structure issue, the format of the online auction also influences the final prices. Most of the online auctions are English- or Dutch-style auctions with a proxy 
bidding capability. A starting level, the minimum bid, is often set as a strategic parameter. A minimum bid exists to censor bidders with extremely low valuations. Auction theory suggests that the minimum bid is binding when the highest order statistic of bids is below the minimum bid. When the highest bid goes above the minimum bid, the minimum bid will not have a direct influence on the final price [Livingston (2005); Yin (2004))]. However, the minimum bid tends to have a direct decreasing influence on the ending price, as found by some studies, although the findings are not conclusive [Lucking-Reiley et al. (2000); Bajari and Hortscsu (2002)].

The undisclosed reservation price is another strategic factor in online auctions. The reservation price has been discussed in the extant literature in the context of bidders' collusive behavior in traditional auctions. Regarding the online auctions, bidders' collusion is unlikely, if not impossible, when the bidders are geographically diverse and can even be from different continents. A recent study by Bajari and Hortacsu [2002] finds that a secret reservation price is often used in the auctions of highly valued products. Katkar and Lucking-Reiley [2000] conducted a field experiment which shows that the reservation price can be used for purposes other than profit maximizing from a seller's perspective. While the secret reservation price plays a similar role as the minimum bid, the effect of the reservation price is more obscure or is more difficult to ascertain in online auctions.

\subsection{Information Asymmetry Theory:}

Information is valuable to all individuals and entities in an economy. However, information asymmetry is pervasive in economic relationships. Akerlof's [1970] result shows that information asymmetry between buyers and sellers can hinder the functioning of a market from where all quality products are traded to the point where only the worst quality goods are 
traded. Similar results are also obtained by Rothschild and Stiglitz [1976] in their analysis of the automobile insurance market. In an online auction market with crowds of sellers and buyers, the physical inspection of a product is a luxury. In order to sustain market efficiency, certain mechanisms are necessary to alleviate the problem of information asymmetry.

The most-studied credibility mechanism for the online auction market is the online feedback system, which serves as an indicator of the trader reputation [Ba and Pavlou (2002); Bolton et al. (2004); Resnick and Zeckhauser (2001) etc.]. Reputation is a traditional mechanism to alleviate the information asymmetry problem [Klein and Leffler (1981); Shapiro (1983)]. In online auctions, reputation is either established through a voluntary word-of-mouth system or through a pre-qualified process by the market makers. Other mechanisms available to online auctions include manufacturer warranty [Gal-Or (1989)], payment methods, and seller history [Zhou, Dresner and Windle (2009)]. In an online environment, the existence of a warranty on a product enhances the authenticity of the product. Handling financial payments via a third party can afford some protection for the bidders in case of a seller' fraud [Melnik and Alm (2002); Eaton (2002); Zhou, Dresner and Windle (2009)]. For example, credit card or escrow service companies can serve as an intermediary to enforce contractual performance. The age of a seller's user ID measures the length of a seller's history. Under the assumption that a disreputable seller is likely to change his or her user ID regularly to avoid being caught, a long tenure in user ID is an indicator of a seller's honesty and consistent performance.

\section{Estimation and Statistic/Econometric Issues}

One of the most important empirical methodologies used in business research is econometric analysis. Econometric models have been extensively employed in studies of 
logistics and supply chain management, for instance, inventory turnover [Gaur et al. (2005)], supply chain technology [Suzuki and Williams 1998), and stock-out responses [Zinn and Liu (2001)]. Data collected from online auctions display complicated statistical properties that pose major challenges to researchers in terms of selecting the appropriate econometric methods. In this section, we will outline the major statistic/econometric issues, present diagnostics and treatments associated with each issue, and discuss how the diagnostics and treatments can be implemented.

\subsection{Regression Model Estimation}

In estimating online auction prices, the ending price of an auction is estimated by regressing the price on a set of theory-suggested variables in the form of:

$$
y=X \beta+\varepsilon
$$

where $y$ is the ending price of an auction and $X$ is the set of prices influencing independent variables. If all the classic assumptions for regression models are met, the Ordinary Least Square (OLS) method generates unbiased and efficient estimators [Greene (2000)]. Due to OLS's simplicity, it has been used to identify auction price determinants [Kalyanam and McIntyre (2001); Eaton (2002); Dewan and Hsu (2004)]. However, not all assumptions are satisfied in estimating online auction data. Therefore, OLS results are often used as the baseline or the starting point for more sophisticated analyses [Livingston 2005; Zhou, Dresner and Windle (2009)].

\subsection{Non-Spherical Disturbances}


One assumption that is often violated in online auctions is that of the spherical disturbance. Instead of having the same variance, i.e., $\operatorname{Var}\left[\varepsilon_{i} \mid X\right]=\sigma^{2}$, the variance of the disturbance term becomes observation-specific, i.e., $\operatorname{Var}\left[\varepsilon_{i} \mid X\right]=\sigma_{i}^{2} . \quad$ Generally, heteroscedasticity does not bias the estimated coefficients. However, one can not draw correct statistical inferences based on tests constructed from the biased variance-covariance matrix. In the context of online auctions, Houser and Wooders [2000] believe that the different auction length imposes a group-wise heteroscedastic structure on the variance-covariance matrix of a regression model.

Ways to deal with heteroscedasticity include visual graphing and statistical tests [White's test) for identification, taking the natural logarithm to reduce the data dispersion, and using the Generalized Least Square (GLS) method to correct for it. Zhou, Dresner and Windle [2009)] did not find any heteroscedasticity issue for their data after employing the above identification methods. In general, a check for heteroscedasticity across different auctions is recommended as a safeguarding step.

\subsection{Data Censoring}

A more complicated issue with the online auction data is data censoring. In online auctions, as a general rule, the ending price takes the value of the minimum bid when the highest bid falls below the minimum bid. Hence, nobody observes the true distribution of the ending prices unless the ending price is higher than the minimum bid, which constitutes a classic data left-censoring problem. Auctions that end with no bids are often suspected to be censored as well [Livingston (2005)]. To reflect such data censoring in our model, let $p^{*}$ denote the true ending 
price and $p$ denote the observed price, and let $c$ denote the seller determined minimum bid. Then, $p^{*}$ is censored by the starting bid $c$ as:

$$
p=p^{*} \text { if } p^{*}>c ; p=c \text { if } p^{*} \leq c
$$

What we observe is only uncensored portion of ending prices. Statistical properties of the censored distribution are different from the true distribution. The marginal effect of an independent variable $x$ is then discounted as:

$$
\partial E[p \mid x] / \partial x=\beta \times \operatorname{prob}\left(p^{*}>c\right)
$$

OLS estimation based on censored data tends to underestimate the marginal effect of the independent variables that can boost a buyer's bids to surpass the starting bid. In the context of online auctions, the effect of the feedback reputation is subject to the data censoring issue [Resnick et al. (2006); Livingston (2005)].

To address the data censoring issue, Tobin [1958] proposed the Tobit model (also called Censored Regression Model). The log-likelihood function for the censored regression model is expressed as:

$$
\log (L)=-\frac{1}{2} \sum_{p_{i}>c}\left[\log (2 \pi)+\log \sigma^{2}+\frac{\left(p_{i}-\beta^{\prime} x_{i}\right)^{2}}{\sigma^{2}}\right]+\sum_{p_{i}=c}\left[1-\Phi\left(\frac{\beta^{\prime} x_{i}}{\sigma}\right)\right]
$$

The first part of the summation corresponds to the log-likelihood function for non-censored observations and the second part of the summary corresponds to the probabilities log likelihood for the censored observations.

Recent research on online auction price determinants has adopted the Tobit model to improve the estimates [Lucking-Reiley et al. (2000); Resnick et al. (2006); Melnik and Alm (2002); Zhou, Dresner and Windle (2009)]. Most of these studies have treated the minimum bid as a censoring point [Lucking-Reiley et al. (2000); Resnick et al. (2006); Melnik and Alm 
(2002)]. One distinction from the classic Tobit model is that the censoring point in online auction studies is not constant across observations. Instead of a fixed constant $c$, the censoring point (the minimum bid) varies by auctions, $c_{i}$. Therefore, most studies have adopted the varying cuttingpoint $\left(c_{i}\right)$ method proposed by Amemiya [1973].

Despite its popularity, the Tobit model is still inadequate to address some of the properties specific to the online auction data. First, the Tobit model assumes a normal distribution that may not be realistic with the auction data [Resnick et al. (2006)]. The study by Zhou, Dresner and Windle [2009] conducted Tobit analyses by assuming normal, logistic, Gamma and Weibull distributions. The signs of the most of the coefficients and their statistical significance stayed unchanged across the different distributions. However, the normality should still be carefully verified in analyzing online auctions using the Tobit model. The second problem associated with the Tobit model is that the Tobit model assumes that auction entries and the ending prices are determined by the same set of variables [Vella (1998)]. In an online auction, variables that trigger bid entries might not determine ending prices as well [Livingston (2005)]. Instead, the incidental truncation model [Greene (2000)] may be more appropriate.

\subsection{Endogenous variables:}

Endogeneity is another econometric issue that deserves very careful consideration in analyzing online auction data. Reasons for variables to be endogenous vary, ranging from sample selection, measurement error and omitted variables to simultaneity. Under endogeneity, OLS results are biased and inconsistent. In this section, we shall discuss endogeneity and its diagnostics in online auction pricing.

Recall that one of the assumptions of the classical regression is: 


$$
E\left[\varepsilon_{i} \mid X\right]=0
$$

It states that the disturbance term has a zero mean conditional on the independent variables. This assumption has a further implication on the relationship between the disturbance term and the independent variables. Note that the covariance between the disturbance term and the independent variables can be written as:

$$
\operatorname{Cov}\left(\varepsilon_{i}, X\right)=\operatorname{Cov}\left(E\left[\varepsilon_{i} \mid X\right], X\right)
$$

Given the assumption $E\left[\varepsilon_{i} \mid X\right]=0$, we obtain that:

$$
\operatorname{Cov}\left(\varepsilon_{i}, X\right)=\operatorname{Cov}\left(E\left[\varepsilon_{i} \mid X\right], X\right)=0
$$

The zero covariance between the disturbance term and the independence variables is a necessary condition for non-existence of endogeneity. This assumption, however, is often violated in online auction price estimations. Although Hausman's specification test [Hausman (1978)] can be used to identify endogeneity, how we should treat the endogeneity issues in estimating online auction data still deserves some further discussion.

\section{Sample selection:}

The first cause of endogeneity is sample selection. Sample selection often results from non-random sampling. In online auctions, sellers with better reputation generally attract more bids than other sellers. Livingston [2005] noticed that some poor reputation sellers also received bids while other poor reputation sellers did not. This led him to believe that there are unobserved factors that pushed the bidder valuation to be higher than the starting bid in auctions put up by some low reputation sellers, but not in auctions by other low reputation sellers. Hence, if only the sample that received at least one bid is included in the analysis, the result can be subject to the sample selection problem, where the variance of the disturbance terms is higher for the low 
feedback reputation sellers than for the high reputation sellers. And the disturbance term is no longer independent from the reputation variable.

Several studies have proposed methods to handle sample selection problem. One way is to explicitly model the sample selection in the framework of the Tobit model (please refer to previous section) or the incidental truncation model [Hans Franses (2005)]. Livingston [2005] adopted the incidental truncation model, where the entry decision and bidding are separately modeled but jointly estimated. For details, please see Greene [2000]. The second method is the instrumental variable method, which we will discuss in the following section.

\section{Measurement error and omitted variables:}

Measurement errors and omitted variables are also causes for endogeneity. The zero covariance assumption between the independent variables and the disturbance term can be violated when the independent variables are measured with errors or important variables are omitted (In general, most of the endogeneity issues can be more or less attributed to the omitted variable problem).

The number of bidders is a variable that can be subject to measurement errors and/or to the omitted variable issues. The number of bidders should influence an auction's ending prices according to auction theory. Yin [2004] discussed the reason why the number of bidders can be endogenous in the pricing function. It is argued that the number of bidders can be endogenous in two ways. First, the number of bidders can be measured with errors since the observed number of bidders may not equal to the actual number of bidders that want to participate in the auction for reasons such as data censoring. In addition, Dougherty and Lohrenz [1977] also suggested that some bidders might not be as serious as others, indicating another source of measurement errors. Secondly, the omitted variable problem plays a role as well. A bidder's decision to enter an 
auction is jointly determined by his expected value on the item and the current highest bid [Milgrom and Weber (1982)]. As a result, some factors that influence the expected value also influence bidder entries. Therefore, the number of bidders is very likely to correlate with the omitted price determinants [Bajari and Hortacsu (2002)].

The instrumental variable method is often used as a treatment to correct the endogeneity problem. The method is to search for an instrumental variable (IV) to replace the endogenous variable. An IV is a variable that is only correlated with the endogenous independent variables but not with the disturbance term. One needs to search for an instrumental variable that is highly correlated with the number of bidders, but is also independent of the ending price.

Instrumental variables, although easily defined in theory, are very difficult to find in practice. Several studies have made attempts to suggest instrumental variables for the number of bidders. Yin (2004) argued that minimum bid can serve as an instrumental variable for the number of bidders. It qualifies for an IV for the number of bidders as long as the minimum bid does not convey any information relevant to the value of an item. However, it should be noted that there are some auctions that have the minimum bid close to the retail value. For example, the minimum bid on a camera with a $\$ 1,000$ retail value is set to be $\$ 500$. In such cases, the minimum bid reflects the value of the item.

Yin [2004] also suggested that using the visitor counter of an auction, the ending time and date, the length of an auction, and the overlap of bidders with other similar auctions as IVs for the number of bidders. Unfortunately, these suggestions are not always feasible. For example, the visitor counter is frequently unavailable in online auctions. Ending time, ending date and auction length, although qualify for IVs due to their independence from the ending price, are still subject to another important criterion for IVs, the explanatory power. In addition to being 
independent from the disturbance term, the explanatory power of an IV is also essentially critical. Bound et al. [1995] shows that the relative inconsistency of the IV to the OLS methods is:

$$
\frac{p \lim \hat{\beta}_{i v}-\beta}{p \lim \hat{\beta}_{o l s}-\beta}=\frac{\sigma_{\hat{x}, \varepsilon} / \sigma_{x, \varepsilon}}{R_{x, z}^{2}}
$$

where $\hat{\beta}_{i v}$ and $\hat{\beta}_{\text {ols }}$ are estimates of $\beta$ using the IV and OLS methods respectively. $\sigma_{\hat{x}, \varepsilon}$ and $\sigma_{x, \varepsilon}$ denote the covariance between $\varepsilon$ and the estimated $\hat{x}$ based on the IV $z$ and the covariance between $\varepsilon$ and_x itself. $R_{x, z}^{2}$ is the $R$-square when $x$ is projected on the IV $z$. The inconsistency is positively correlated with $\sigma_{\hat{x}, \varepsilon}$ and negatively correlated with $\sigma_{x, \varepsilon}$ and $R_{x, z}^{2}$. As a result, a weak $R$-square of $x$ (an endogenous variable) projected on $z$ (the IV) can exaggerate the effect of any correlation $z$ may have on $\varepsilon$. Therefore, an IV should be carefully selected to satisfy both the independence to $\varepsilon$ and the explanatory power on $x$.

The best IV candidate among Yin's [2004] list may be the number of bidders in auctions of similar values. The number of bidders received by similar auctions is less likely to possess strong correlation with the value attributes of the auction of interest. Yin [2004] derived this variable using an outside survey, which is independent of the online auction being studied and is exogenous. Given the identified IVs, Least Square using the IV or the generalized method of moments (GMM) can be used to estimate the ending price.

\subsection{Non-parametric methods:}

So far, all previously discussed methods employed parametric methods where an ex-ante distribution is required. For instance, the regression models most often assumed data is 
asymptotically normal and the TOBIT model is also based on normal distributions. The required distribution at the beginning very often constrained model theoretical base and estimation accuracy [Bajari and Hortacsu (2005)]. In their 2005 research, Bajari and Hortacsu estimated several non-parametric models to attest to the point of bidder rationality. Both rationality assumption models were tested using non-parametric methods due to the relaxed assumption on valuation distribution. In the third model they estimated, the learning method introduced by Sargent [1993] was used due to its adaptive learning assumption that could better fit the reality of online auctions. In this case, bidder belief is assumed to be formulated through previous experiments. For more detailed discussion of non-parametric auction estimations, please refer to Athey and Haile [2005].

In summary, the above sections have identified three key statistical/econometric issues in online auction pricing studies, namely, heteroscedasticity, data censoring and endogeneity. More importantly, we have also identified and discussed the existing treatments for these issues. Future research and procurement studies can benefit from this section by checking how existing research have treated the issues and how researchers have operationalized their measurements. Practically, it is rare for a study to deal with all of the above issues. Researchers should prioritize their needs in order to best answer the research question.

\section{Determinants of the Online Auction Price}

In this section, auction price determinants identified by the existing literature are summarized and analyzed. For each of the determinants, we further discuss their implications. For those that are not in line with theoretical propositions, we offer explanations for the outcomes and for how these determinants can be better explored. 
As predicted by the hedonic price model, product characteristics are shown to be significant determinants of ending prices in the current literature. For example, Livingston [2005] established significant effects on the price of golf clubs of such product characteristics as left hand, right hand or senior clubs. The Melnik and Alm [2002] study finds whether a trust the information disclosed by sellers to a large extent. Other than specific product characteristics, product condition, e.g., new or used, has remained consistently significant across various studies [Bajari and Hortacsu (2002); McDonald and Slawson (2002); Kalyanam and McIntyre (2001); Livingston (2005); Zhou, Dresner and Windle (2009)]. In addition, information presentation accuracy has been explicitly studied by Kalyanam and McIntyre [2001], Melnik and Alm [2002], Eaton [2002] and Yin [2004]. Most of the studies, except one, confirmed the positive relationships between information accuracy and the ending prices.

How the information structure variables influence the final price is not as clear as the hedonic pricing variables do. This is due to the assumptions on the information structure, i.e., the private value or the common value. Some research identifies the number of bids as price determinants [Dewan and Hsu (2004); Kalyanam and McIntyre (2001)]. However, the number of bids is to the best an imperfect proxy for the number of bidders. Bajari and Hortacsu [2002] find that the number of bidders reduces the normalized bid, which provides suggestive evidence to support the common value assumption. Yin [2004] also obtained similar results as Bajari and Hotascu [2002]. However, the actual relationship between the number of bidders and the ending price may be a non-linear curve or a combination of the private value and the common value assumptions.

The market value or the retail value of an object is predicted to positively affect the ending price. Empirical results confirm this prediction in all studies [Lucking-Reiley et al. 
(2000); Dewan and Hsu (2004); Yin (2004), etc.]. For the effect of the minimum bid, although Bajari and Hortacsu's [2002] result indicated that the minimum bid has a positive effect on the ending price, theoretically it should not have any direct influence on the ending price as soon as the other bids surpass it. Livingston [2005] and Yin [2004] both claim that the minimum bid does not have any direct influence on the ending price. Instead, they claim that it can be an influential factor for the initial entry. The effect of the secret reservation price on the ending price is also ambiguous. While some studies find it significant and positive [Lucking-Reiley et al. (2000); Livingston (2005)], others find it significant and negative [Bajari and Hortacsu (2002)].

The theory on information asymmetry also provides guidance on the study of online auction price determinants. Most of the research has focused on digital reputation, i.e., feedback system. Current research results on feedback are still mixed [Resnick et al. (2006); Dellarocas 2003)]. For instance, some research finds that sellers'good reputation increases the ending price, while other research did not. The feedback reputation only partially influences the ending price. Zhou, Dresner and Windle [2009)] believes a first step to reduce the inconsistency is to use more consistent measurements and estimation methods. Feedback can be measured by the number of pieces of positive feedback, the percent of positive feedback, the percentile of the positive feedback, or feedback scores calculated by the auction websites involved. Apart from measurements, different estimation methods, model specifications and target products can further confound the results.

The sellers' reputation effect on the auction prices is also weak. Lucking-Reiley et al. [2000] finds that the marginal effect of negative feedback was only $-\$ 0.0085$. In the research by McDonald and Slawson [2002], the coefficients for positive and negative feedback were $\$ 0.028$ 
and $-\$ 0.018$ respectively. Reputation appears to be statistically significant but not economically significant. Other than the measurement issues, how the feedback reputation is constructed certainly reduces its economic significance. Regressing a variable that is at the maximum around one thousand on an independent variable that is in tens of thousands certainly dilutes the marginal effect. Thus, the weak marginal effect does not directly lead to reputation ineffectiveness.

There are other trust-enhancing mechanisms that are often over-looked in empirical studies. One of them is the usage of credit cards. Credit card usage helps buyers reduce economic loss from fraud. Zhou, Dresner and Windle's study [2009)] finds the capability of using credit card for payments is a consistently significant variable across different functional forms and estimation methods. The same study also tested the effect of the product warranty, which is found to be a valuable factor in determining the ending prices. In addition, the study also finds that long ID age helps to increase ending prices of an auction.

\section{Conclusions, Managerial Implications and Future Research}

The pricing mechanism in online auction markets is guided mainly by three theories, hedonic pricing, auction theory and information asymmetry theory. Each theory suggests a set of price influencing factors that should be considered in empirical studies. However, due to the context within which the factors are proposed, it is challenging to test these factors empirically. Our review of these empirical studies shows that data censoring and endogeneity are the two most critical issues in the estimation of online auction prices. Heteroscedasticity, although simple to treat, also deserves special caution. Researchers mostly used conventional empirical methods to diagnose and treat the statistical/econometric issues. For the Tobit model, online auction data 
requires the usage of the varying-cutting-point method instead of a fixed-cutting-point estimation. Moreover, normality is often a concern raised by the extant studies [Resnick et al. 2006; Zhou, Dresner and Windle (2009)]. In dealing with the sample selection problem, the incidental truncation model is often used [Livingston (2005)]. Instead of assuming the same set of variables that influence both the entry and bidding, incidental truncation models individually estimate the two decisions. Measurement errors and omitted variables are also reasons that lead to endogeneity in estimating the online auction data, where the instrumental variable method can be used. The challenge lies more on the selection of an appropriate IV. We applaud the novel way used by Yin [2004] to use outside survey methods in constructing an IV. However, the luxury to run an outside survey is not always available. We believe that the number of bids received by similar auctions can be a good substitute that is easier to collect. In addition, how a study is operationalized and how the samples are selected can affect the statistical/econometric complexity. For instance, if a study only uses the auctions of brand new items or only the unbundled auctions, the sample selection process, although convenient, may carry biases that are yet to be well explored. The decision of bundling and selling used items can be endogenous factors to consider as well.

Although this review may not be exhaustive to cover all studies from every related field of studies, our findings still constitute a comprehensive basis for understanding and developing a framework for online auction pricing. Through the analysis and discussion of existing studies, the following points concerning the online auctions and the price determinants can be concluded:

- Information in large-scale online auctions is trusted, where the price closely reflects the value of a product. All significance of hedonic price variables and the retail price corroborate the credibility of information in online auctions [Kalyanam and McIntyre 
(2001); Melnik and Alm (2002); Eaton (2002); Zhou, Dresner and Windle (2009)]. The large-scale online sourcing is a viable channel.

- Winner's curse is a concern for online bidders, the risk of over-bidding cannot be overlooked: existing empirical work that better measures the effect of the number of bidders favors the common value assumption and the existence of winner's curse [Bajari and Hortacsu (2002); Yin (2004)]. Therefore, sourcing through online auctions does carry the risk of over-bidding. For some firms, this risk can greatly shrink the cost savings which are usually the initial motivation for online sourcing.

- Transaction security is highly valued, where the price is a function of both product value and trader honesty. Although the information is trusted, transaction security concerns, such as online frauds, needs to be carefully addressed. The prevalence of the online feedback system, the pre-qualification of suppliers, and the preference for third party payments [Zhou, Dresner and Windle (2009)] demonstrate the relentless effort online firms are taking to enhance transaction security. In addition, traditional means, such as warranty and firm age, are necessary and convenient tools to build trust.

- The effects of auction parameters, such as the secret reservation price and the minimum bid, on online auction pricing are still unclear. The secret reservation price and the minimum bid should be carefully set as strategic options. For instance, Zhou [2006)] shows that a secret reservation price does not always benefit the seller. A seller has to align well the usage of a secret reservation price with the market dynamics in order to gain higher profits. The minimum bid, however, may not even be a price influencing factor at all. Instead, it may simply serve as an entry censor [Livingston (2005); Yin (2004)]. 
For logistics/supply chain professionals and firms that are interested in participating in online auctions, the following managerial implications can be useful for logistics and procurement decision making:

- The presentation of a product the clear analysis of the procurement needs should be thoroughly studied before engaging in online auctions. Given that physical inspection is less likely online and posted information is trusted to a large extent, vague descriptions in an online auction may only lead to unpleasant surprises that can disrupt the procurement prices and processes.

- A procurement manager that uses online auctions as a procurement channel faces the tradeoff between satisfying the urgency of a procurement need and the winner's curse. A thorough research on the supply market and a well-set upper limit of bids are good practices that can potentially enhance the procurement efficiency.

- For selling firms, an over-focus on attracting bidders may inversely influence the performance of an auction. When the winner's curse drives the price too low in a reverse auction, the quality of products or services can be compromised.

- Although the procurement cost should be as low as possible, the cost saving should not always assume higher weight than the supplier credibility or capability. Even for pre-qualified suppliers, caution should still be exercised to avoid opportunistic traders. References from a third party or a payment method involving a third party can be beneficial to both sides.

We also find the following dimensions of online auction pricing not fully explored. First, data collected directly from the markets are representative of the market reality. A controlled experiment can better focus on a specific aspect. For example, Bolton et al. [2004] designed a 
lab experiment to study the effect of reputation on not only prices, but also market efficiency. Experiment results may better reinforce the existing results of the online auction pricing. Second, the auction theory did not offer clear answers for the use of the reservation price [Bajari and Hortcsu (2002)]. How the secret reservation price should influence auction prices is a topic that needs further exploration. Third, market dynamics are often ignored in the current literature. How the market structure and the competitive forces influence auction prices should be explored. Fourth, the online reputation system remains a puzzle unsolved. How robust the system is against the participant behavior variation is not touched [Dellarocas (2003)]. In addition, multi-item auctions are increasingly important in online auctions. Strategic options such as the bid increment [Bapna, et al. (2002)] deserve more thorough exploration as well. 


\section{References}

Akerlof, G. (1970). The market for 'lemons': Quality uncertainty and the market mechanism. The Quarterly Journal of Economics, 84: 488 - 500.

Amemiya, T. (1973). Regression analysis when the dependent variable is truncated normal. Econometrica, 41: 997-1016.

Athey, S. and P. Haile. (2005). Non-parametric approaches to Auctions. Handbook of Econometrics, Vol 6.

Ba, S. and Pavlou, P. (2002). Evidence of the effect of trust building technology in electronic markets: Price premiums and buyer behavior. MIS Quarterly, 26: 243-268.

Bajari, P. and Hortacsu, A. (2002). The winner's curse, reserve prices and endogenous entry: Empirical insights from eBay auctions. Working paper, Department of Economics, Stanford University.

Bajari, P. and Hortacsu, A. (2005). Are structural estimates of auction models reasonable? Evidence from experimental data. Journal of Political Economy. 113: (4).

Bakos, Y. (1998). The emerging role of electronic marketplaces on the Internet. Communications of the ACM, 41: $35-42$.

Bapna, R., Goes, P, Gupta, A, and Karuga, G. (2002). Optimal Design of the Online Auction Channel: Analytical, empirical, and computational insights. Decision Sciences, 33: 557 - 577.

Bolton, G., Katok, E., and Ockenfels, A. (2004). How effective are online reputation mechanisms? An experimental investigation. Management Science, 50: 1587-1602.

Bound, J., Jaeger, D. and Baker, R. (1995). Problems with instrumental variables estimates when the correlation between the instruments and endogenous explanatory variable is weak. Journal of the American Statistical Association, 90: 443-450.

Boyer, K. and Olson, J. (2002). Drivers of Internet Purchase Success. Production and Operations Management, 11: 480 - 498.

Brynjolfsson, E. and Smith, M. (2000). Frictionless Commerce? A Comparision of Internet and Conventional Retailers. Management Science, 46: 563 - 585.

Capen, E., Clapp R. and Campell, W. (1971). Competitive bidding in high-risk situations. Journal of Petroleum Technology, 23: 641-653.

Dallarocas, C. (2003). The digitization of word of mouth: Promise and challenges of online feedback mechanisms. Management Science, 49: 1407-1424. 
Dewan, S. and Hsu, V. (2004). Adverse selection in electronic markets: Evidence from online stamp auctions. Journal of Industrial Economics, 52: 497-516.

Dougherty, E. and Lohrenz, J. (1977). Money left on the table in sealed, competitive bidding: Federal offshore oil and gas lease bids. Proceedings of Petroleum Engineers Meeting, Dallas, TX.

Eaton, D. (2002). Valuating information: Evidence from guitar auctions on eBay. Working paper, Department of Economics, Murray State University.

Ellram, L. (1996). A structured method for applying purchasing cost management tools. International Journal of Purchasing and Materials Management, 32: 11 - 19.

Emiliani, R. and Stec, D. J. (2002). Realizing Savings from Online Reverse Auctions. Supply Chain Management, 7: $12-23$.

Forgionne, G. (1996), "Forecasting army housing supply with a DSS-delivered econometric model.” Omega, 24: 561 - 575

Fudenberg, D. and Tirole, J. (2000). Game theory. The MIT Press, London.

Gal-Or, E. (1989). Warranties as a signal of quality. The Canadian Journal of Economics, 22: 50 -61 .

Gaur, V., Fisher, M. and Raman, A. (2005). An econometric analysis of inventory turnover performance in retail services. Management Science, 51: 181 - 194.

Germer, T., Carter, C. and Kaufmann, L. (2004). Purchasing Auctions - A Synthesis of Current Research, Proceedings of the 15th Annual North American Research Symposium on Purchasing and Supply Management, Tempe, Arizona: Institute of Supply Management, March 2004,120139.

Greene, W. (2000). Econometric Analysis. Prentice-Hall, New Jersey.

Hans-Franses, P. (2005). On the use of econometric models for policy simulation in marketing. Journal of Marketing Research, 42: 4-14.

Hausman, J. (1978). Specification Tests in Econometrics. Econometrica, 46: 1251 - 1271.

Houser, D. and Wooders, J. (2000). Reputation in auctions: Theory and evidence from eBay. Working paper, Department of Economics, University of Arizona.

Johnson, F. and Klassen, R. (2005). E-Procurement. MIT Sloan Management Review, 46: 7 - 13. Kalyanam, K. and McIntyre, S.(2001). Return on reputation in online auction markets. Working paper, Department of Marketing, Santa Clara University. 
Kaplan, S. and Sawhney, M. (2000). E-Hubs: The New B2B Marketplaces. Harvard Business Review, May-June, 97 - 103.

Katkar, R. and Lucking-Reiley, D. (2000). Public versus secret reserve prices in eBay auctions: Results from a Pokemon field experiment. NBER Working Paper, No. 8183.

Kawtummachai, R. and Hop, N. (2005). Order allocation in a multiple-supplier environment." International Journal of Production Economics, 93: 231 - 238.

Klein, B. and Leffler, K. (1981). The role of market forces in assuring contractual performance. The Journal of Political Economy, 89: 615 - 641.

Lancaster, K. (1966). A new approach to consumer theory. Journal of Political Economy. 74: 126.

Livingston, J. (2005). How valuable is a good reputation? A sample selection model of Internet auctions, The Review of Economics and Statistics, 87: 453 - 465.

Lucking-Reiley, D., Bryan, D, Prasad, N, and Reeves, D. (2000). Pennies from eBay: The determinants of price in online autions. Working paper, Department of Economics, Vanderbilt University.

Martins-Filho, C. and Bin, O. (2005). Estimation of hedonic price functions via additive nonparametric regression. Journal of Empirical Economics, 30: 93 - 114.

McDonald, C. and Slawson, C. (2002). Reputation in an Internet auction market. Economic Inquiry. 40: $633-650$.

Melnik, M. and Alm, J. (2002). Does a seller's ecommerce reputation matter? Evidence from eBay auctions. Journal of Industrial Economics, L (3): 337-349.

Milgrom, P. and Weber, R. (1982). A theory of auctions and competitive bidding. Econometrica, 50: $1089-1122$.

Milgrom, P. (2004). Putting auction theory to work. Cambridge University Press, Cambridge, UK.

Murphy, N.., Soni, S. and Ghosh, S. (2004), A framework for facilitating sourcing and allocation decisions for mark-to-order items. Decision Sciences, 35: 609 - 637.

Pakes, A. (2001). A reconsideration of hedonic price indices with an application to PCs. Working Paper, Harvard University.

Paarsch, H. (1992). "Deciding between common values and private value paradigms in empirical models of auctions." Journal of Econometrics, 51: 191-215. 
Resnick, P. and Zeckhauser, R. (2001). Trust among strangers in Internet transactions: Empirical analysis of eBay's reputation system. Working paper, School of Information, University of Michigan.

Resnick, P., Zeckhauser, R, Swanson, J, and Lockwood, K. (2006). "The value of reputation on eBay: A controlled Experiment." Experimental Economics, 9(2), 79 - 101.

Rosen, S. (1974). Hedonic prices and implicit markets: Product differentiation in pure competition. Journal of Political Economy, 82: 35-55.

Rothschild, M. and Stiglitz, J. (1976). Equilibrium in competitive insurance markets: An essay on the economics of imperfect information. The Journal of Industrial Economics, 90: 630 - 649.

Sargent, T. J. (1993). Bounded Rationality in Macroeconomics. Laserscript.

Shapiro, C. (1983). Premiums for high quality products as returns to reputation. The Quarterly Journal of Economics, 98: 657 - 679.

Smichi-Levy, D., Kaminsky, P. and Smichi-Levi, E. (2003). Designing \& managing the supply chain: Concepts, strategies \& case studies. McGraw-Hill, New York, 165 - 190.

Suzuki,Y. and Williams, L. R. (1998). Analysis of EDI resistance behavior. Transportation Journal, 37: 36 - 44 .

Tobin, J. (1958). Estimation of relationships for limited dependent variables. Econometrica, 26: 24-36.

Vella, F. (1998). Estimating models with sample selection bias: A survey. Journal of Human Resources, 33: 127-167.

Yin, P. (2004). Information dispersion and auction prices. Working paper, Department of Economics, Stanford University.

Zhou, M., Dresner, M. and Windle, R. (2009). Revisiting feedback system: Trust building in digital markets. Information and Management, 46: 279-284.

Zhou, M. (2006). Simultaneous online auctions: Competing reservation prices. Proceedings of Decision Sciences Institute Annual Conference, San Antonio, TX.

Zinn, W. and Liu, P. C. (2001). Consumer response to retail stockouts" Journal of Business Logistics, 22: 49-71. 